\title{
A cobertura jornalística do caso Mayara Amaral: reflexões sobre um feminicídio anunciado
}

\section{THE NEWS COVERAGE OF THE MAYARA AMARAL CASE: REFLECTIONS ABOUT AN ANNOUNCED FEMINICIDE}

\section{Katarini Giroldo Miguel}

Jornalista, mestre em Comunicação pela Universidade Estadual Paulista, Campus Bauru, doutora em Comunicação pela Universidade Metodista de São Paulo, docente no curso de Jornalismo e no mestrado em Comunicação da Universidade Federal de Mato Grosso do Sul.

E-mail: katarini.miguel@ufms.br

\section{Tainá Mendes Jara}

Jornalista, mestranda em Comunicação (linha de pesquisa: Linguagens, Processos e Produtos Midiáticos) do Programa de Pós-Graduação em Comunicação da Universidade Federal de Mato Grosso do Sul. E-mail: tainajara@gmail.com

\section{Lynara Ojeda de Souza}

Jornalista, mestranda em Comunicação (linha de pesquisa: Linguagens, Processos e Produtos Midiáticos) do Programa de Pós-Graduação da Universidade Federal de Mato Grosso do Sul. E-mail: lynaraojeda@gmail.com

Recebido em 24 de janeiro de 2018. Aprovado em 2 de abril de 2018.

\section{Resumo}

Trazemos para este trabalho uma discussão jurídica e conceitual da violência contra a mulher, atrelada à análise exploratória e comparativa da cobertura jornalística de um caso específico de feminicídio: da musicista campo-grandense Mayara Amaral, que colocou em debate o uso da tipificação, além da própria abordagem midiática. Selecionamos as notícias sobre o caso em veículos on-line de diferentes perfis editoriais: Campo Grande News, Folha de S.Paulo, El País Brasil e revista Veja, e constatamos pautas diretamente influenciadas pelas mobilizações sociais em rede, preocupadas em noticiar o crime, mas não em contextualizar suas motivações.

Palavras-chave: Cobertura jornalística

Feminicídio. Violência contra a mulher. 


\section{Abstract}

We bring to this article a legal and conceptual discussion of violence against women, coupled with the exploratory and comparative analysis of the journalistic coverage of a specific case of femicide: from the musician Mayara Amaral, who put in debate the use of typification, as well as the media approach. We selected the news about the case in vehicles of different editorial profiles: Campo Grande News, Folha de S.Paulo, El País Brasil and Veja Magazine, and we found patterns directly influenced by social mobilizations on the web, concerned with reporting the crime, but not with contextualizing its motivations.

Keywords: News coverage. Femicide. violence against women.

\section{'A Mulher do Fim do Mundo'}

A Lei n. 13.104, de 9 de março de 2015, institui no Código Penal Brasileiro o assassinato de mulheres como crime hediondo, e o tipificou como feminicídio - qualificado por razões de ser do sexo feminino -, em especial, quando envolve violência doméstica e familiar; menosprezo ou discriminação à condição de mulher (BRASIL, 2015). As penalizações mais específicas e severas em casos de violência contra a mulher já estavam pautadas na Lei Maria da Penha, Lei n. 11.340/06 (BRASIL, 2006), e avançaram constitucionalmente com a Lei do Feminicídio, na tentativa de conter uma realidade deplorável: dados do Mapa da Violência (WAISELFISZ, 2015) indicam que 13 mulheres são assassinadas por dia no Brasil.

A mulher do fim do mundo, título de uma canção interpretada pela cantora Elza Soares e de um álbum militante, lançado em 2015 com mesmo nome, aqui emprestado para essa introdução e para os subtítulos deste trabalho, tem um valor simbólico: dar visibilidade para a causa, a partir de uma expressão artística que denuncia a prática criminosa de violência de gênero. A mulher é a musicista Mayara Amaral. O fim do mundo se deu no dia 25 de julho de 2017, quando ela foi encontrada morta, carbonizada em uma área isolada no município de Campo Grande (MS). Investigações da polícia concluíram que ela foi assassinada no dia 23 de julho, com golpes de martelo, em um motel, com a participação de três homens, inclusive que um deles mantinha envolvimento amoroso com a vítima (este último, posteriormente, assumiu sozinho a autoria do crime). Ainda assim, o caso foi configurado como latrocínio, roubo seguido de morte, já que um carro foi roubado e vendido na sequência. A tragédia ganhou as manchetes, primeiramente, dos jornais campo-grandenses, que negligenciaram o evidente caso de feminicídio. A pressão 
de movimentos e grupos feministas nas redes sociais digitais ${ }^{1}$ e, em especial, uma carta aberta publicada pela irmã da vítima ${ }^{2}$, provocou um contra-agendamento e fez a mídia local rever sua cobertura e abordar o feminicídio. Impulsionado pela dinâmica das redes, o caso conseguiu repercussão nacional e alcançou veículos de grande circulação como revista Veja e Folha de S.Paulo.

O fato, em especial a repercussão citada anteriormente, evidenciou uma oportunidade de se voltar para a cobertura midiática e entender o papel dos veículos de comunicação nesse processo e os diferentes fluxos informativos que ajudam não só na construção de uma notícia, mas na própria representação social da violência contra a mulher. Para tanto, buscamos conceituar neste artigo o termo feminicídio em uma perspectiva jurídica e reflexiva; abordamos o papel que os meios de comunicação exercem ao pautarem assuntos de impacto social e grande violação, além de contextualizarmos a repercussão da mobilização social nesse processo, sinalizando para as possíveis alterações que ocorrem no agendamento do tema quando no ciberespaço, e sob influência da atual vigilância das redes sociais (CASTELLS, 1999; PADILHA, 2012; SAFFIOTI, 2004).

Em um segundo momento, coletamos quatro textos jornalísticos, sendo três deles publicados em veículos de comunicação nacionais que repercutiram o crime ${ }^{3}$ (Folha de S.Paulo, El País e revista Veja) e uma divulgação local (Campo Grande News), feita logo após o crime. O corpus, para o escopo deste artigo, contemplou diferentes abordagens, perfis editoriais, fluxos comunicacionais, e, sobretudo, despontou como relevante para nossas escolhas enquanto pesquisadoras autônomas e mulheres. Procedemos com uma análise exploratória, de teor descritivo, estabelecendo comparações possíveis entre os textos selecionados. O caráter exploratório nos permitiu examinar diferentes faces relativas ao fenômeno estudado; a descrição ajudou nessa tarefa e a revelar associações entre as variáveis do caso e das mídias (GIL, 2010). Além disso, a exploração tem como fundamento percorrer o tema e construir hipóteses, o que, a nosso ver, dialogou com a própria hipótese de agendamento que não pressupõe um modelo fechado.

1 A partir de Recuero (2010), entendemos redes sociais/digitais como um sistema de comunicação pela internet que conecta rede de pessoas/conjunto de atores e suas conexões. No caso dessa cobertura, estamos tratando mais especificamente da plataforma Facebook, mas não podemos eliminar do horizonte as outras redes em que $\mathrm{o}$ assunto pode ser divulgado.

2 A carta publicada em 27 de julho de 2017 no Facebook por Pauliane Amaral, irmã da vítima, na qual contesta a versão de latrocínio e cobra a tipificação de feminicídio. Dias depois, a carta foi editada e o trecho em que dizia que o crime era um feminicídio foi trocado por "crime de ódio contra as mulheres". A mudança pode se dar pelo fato de a tipificação de latrocínio prever uma penalidade maior que o feminicídio. Latrocínio, de 20 a 30 anos de reclusão, e feminicídio, de 12 a 20 anos de reclusão, segundo o Código Penal Brasileiro.

3 Dentro dos limites de um rastreamento feito pela internet, a partir do monitoramento das redes sociais digitais e em sites de busca, identificamos que foram os únicos textos jornalísticos publicados sobre o caso em veículos nacionais e pautados diretamente pela carta da irmã da vitima, por isso da nossa escolha. 
Os jornais locais iniciaram suas coberturas tão logo o corpo foi encontrado, mas o crime ganhou visibilidade nacional justamente após a publicação da irmã da vítima no Facebook, em 27 de julho de 2017, portanto, não seguimos uma data comum para as análises. Até porque, os veículos nacionais fizeram publicações pontuais, motivadas, especialmente, pela comoção das redes, e incorporamos essa especificidade, mas averiguamos, sobretudo, que a tragédia atendeu perfeitamente os critérios de valoração noticiosa, mas não se livrou da interpretação reduzida e distorcida. Para dar início ao entendimento da questão, na sequência tratamos propriamente do enquadramento feminicídio e das dificuldades para uma abordagem jornalística complexa.

\section{'Cê vai se arrepender de levantar a mão pra mim'}

O Código Penal Brasileiro dispõe de dois importantes e recentes mecanismos no combate à violência contra a mulher. Teve início em 2006, com a sanção da Lei n. 11.340, de 7 de agosto de 2006, a Lei Maria da Penha, que aumenta o rigor das punições sobre crimes domésticos, e é aplicada a homens que agridem psicologicamente e fisicamente uma mulher (BRASIL, 2006). Quase dez anos depois, foi sancionada a Lei do Feminicídio, Lei n. 13.104, de 9 de março de 2015, medida que classifica o homicídio de mulheres como crime hediondo e com agravantes quando em situações específicas de vulnerabilidade, tais quais: gravidez, menor de idade, na presença de filhos etc. (BRASIL, 2015). "Entende a lei que existe feminicídio quando a agressão envolve violência doméstica e familiar, ou quando evidencia menosprezo ou discriminação à condição de mulher, caracterizando-se crime por razões de condição do sexo feminino" (WAISELFISZ, 2015, p. 7).

Para entender a existência e a necessidade de aplicação dessas leis, é preciso entender a sociedade sob a ótica de uma perspectiva crítica de gênero (apesar do termo ter sido retirado do texto final da Lei do Feminicídio, devido às pressões da bancada religiosa). A substituição do gênero pela expressão "condição do sexo feminino" limita o significado e fortalece a ideia de que sexo é um conceito biológico, natural, dessa forma, ocultando que há uma construção social e relações desiguais de poder que resultam em ações violentas. Saffioti (2004) propõe uma reflexão mais problematizadora situando o gênero a partir de uma sociedade de classes, capitalista, e fundada na estrutura patriarcal. Para ela, a caracterização "violência de gênero" não é capaz de abarcar a carga histórica que perpassa as agressões de toda a espécie contra a mulher. O conceito deve explicitar a desigualdade entre homens e mulheres e reconhecer a influência do patriarcado. 
Em geral, pensa-se ter havido primazia masculina no passado remoto, o que significa, e isto é verbalizado oralmente e por escrito, que as desigualdades atuais entre homens e mulheres são resquícios de um patriarcado não mais existente ou em seus últimos estertores. De fato, como os demais fenômenos sociais, também o patriarcado está em permanente transformação. Se, na Roma antiga, o patriarca detinha poder de vida e morte sobre a sua esposa e seus filhos, hoje tal poder não mais existe, no plano de jure. Entretanto, homens continuam matando suas parceiras, às vezes com requintes de crueldade, esquartejando-as, ateando-lhes fogo, nelas atirando e as deixando tetraplégicas etc. O julgamento destes criminosos sofre, é óbvio, a influência do sexismo reinante na sociedade, que determina o levantamento de falsas acusações - devassa é a mais comum - contra assassinada. A vítima é transformada rapidamente em ré, procedimento este que consegue, muitas vezes, absorver o verdadeiro réu. Durante longo período, usava-se, com êxito, o argumento de legítima defesa da honra, como se esta não fosse algo pessoal e, dessa forma, pudesse ser manchado por outrem. Graças a muitos protestos feministas, tal tese, sem fundamento jurídico ou de qualquer outra espécie, deixou de ser utilizada. O percentual de condenações, contudo, situa-se a aquém do desejável. (SAFFIOTI, 2004, p. 48)

Nesse sentido, as duas leis servem não apenas para punir os que praticam esses crimes, mas são oportunidades para tirar o problema da invisibilidade. Além disso, são instrumentos para dimensionar a violência contra as mulheres no país e, consequentemente, podem balizar o aprimoramento de políticas públicas para coibir e prevenir tais práticas.

O Mapa da Violência sobre homicídios de mulheres apresentou o quantitativo dessas mortes no intervalo de 1980-2013. Pelos registros do Sistema de Informação de Mortalidade (SIM), nesse período, mais de 106 mil mulheres foram assassinadas. Efetivamente, o número de vítimas passou de 1.353 mulheres, em 1980, para 4.762, em 2013, um aumento de 252\%. A taxa, que em 1980 era de 2,3 vítimas por 100 mil, passou para 4,8 em 2013, um aumento de 111,1\% (WAISELFISZ, 2015, p. 11). No mesmo relatório, Mato Grosso do Sul apresentou a nona maior taxa feminicídio - são 5,9 casos para cada 100 mil habitantes, enquanto a capital, Campo Grande, ficou na $23^{\mathrm{a}}$ posição.

A partir da Lei Maria da Penha, foi possível estabelecer parâmetros que, inclusive, costumam preceder a ocorrência do feminicídio, compondo o chamado ciclo de violência. A lei evidencia que a violência não é somente física, mas pode ser "qualquer ação ou omissão baseada no gênero, incluindo, sofrimento psicológico ou dano moral ou patrimonial, no âmbito da unidade doméstica, da família ou em qualquer relação íntima de afeto, independente da orientação sexual" (PRADO; SANEMATSU, 2017, p. 16). Apesar de considerar que a violência pode ocorrer dentro de qualquer relação íntima, a aplicação da Lei Maria da Penha, na maioria das vezes, passa a ter acompanhamento do Estado quando ocorre dentro de uma estrutura familiar que, assim como o conceito de gênero, é socialmente estabelecida. Com isso, pessoas em outros tipos 
de relação, como por exemplo, sexo casual ou relação homossexual, ainda não se veem amparadas juridicamente.

Os questionamentos em relação à tipificação do assassinato da musicista Mayara Amaral como crime de feminicídio, esbarram em padrões sociais que limitam a aplicação mais efetiva da lei. A investigação da polícia enquadrou o caso como um crime de latrocínio, roubo seguido de morte, uma vez que o suspeito levou o carro da vítima, negociou sua venda e subtraiu outros pertences de Mayara. Embora o crime tenha apresentado aspectos muito mais explícitos de feminicídio, tal hipótese não foi considerada de imediato pela polícia, nem pela mídia, que baseou suas apurações em fontes oficiais. O contexto de uma sociedade machista e patriarcal nos saltou como um dos principais motivos que levaram esta linha de investigação a ser inicialmente ignorada. Na sequência, rememoramos o caso, as motivações para reconhecê-lo (ou não) enquanto feminicídio, inclusive como potência política (MARTINS; CARVALHO, 2016), e o papel das redes sociais digitais nesse processo.

\section{'E o que me fez morrer. Vai me fazer voltar'}

As primeiras apurações do crime foram apresentadas pela polícia em coletiva de imprensa que contou com a presença dos três suspeitos de matar a musicista. Na ocasião, foram revelados fatos com base, principalmente, no depoimento do suspeito, portanto, uma primeira e parcial versão do caso. Diante disso, diversos aspectos irrelevantes foram expostos e contribuíram para um julgamento da própria vítima: o assassinato ter acontecido em um motel; o suposto sexo a três entre a vítima e dois dos suspeitos antes de ser morta; a relação informal que ela tinha com o assassino; e o suposto uso de drogas por Mayara na noite do crime. Os elementos podem ser importantes para montar o quebra-cabeça da investigação, mas não se mostram eficazes, por exemplo, para alcançar uma resposta judicial à altura do crime. Além disso, apesar desses aspectos terem sido amplamente explorados pelos veículos de imprensa, não acrescentam informações ao caso nem revelam interesse público.

Com esse cenário inicial, verificamos problemas éticos em duas instituições que deveriam zelar pela preservação da imagem da vítima: o Estado, representado pela Polícia Civil, e a Imprensa. Os jornais locais acabaram reproduzindo o discurso repassado pela polícia, confiando no suspeito, e gerando conteúdo que fere o próprio Código de Ética dos Jornalistas Brasileiros (FENAJ, 2007). Vejamos que o artigo $6^{\circ}$ do citado código estabelece como dever do jornalista "divulgar os fatos e as informações de interesse público"; "respeitar o direito à intimidade, à privacidade, à honra e à imagem do cidadão"; além 
de "defender os direitos do cidadão, contribuindo para a promoção das garantias individuais e coletivas, em especial as das crianças, adolescentes, mulheres, idosos, negros e minorias"; e "combater a prática de perseguição ou discriminação por motivos sociais, econômicos, políticos, religiosos, de gênero, raciais, de orientação sexual, condição física ou mental, ou de qualquer outra natureza".

Nesse caso, constatamos que, além de ser morta, Mayara passou por um processo de violência institucional, comum em casos de feminicídio. Foram explorados fatos da vida íntima e, principalmente, do comportamento sexual da vítima. Não se preservou sua privacidade, com isso ela foi revitimizada na violação de seu direito à memória, levando a um processo de linchamento moral que causou extremo sofrimento aos amigos e familiares.

Foi justamente esse julgamento e a tentativa de culpabilização da vítima que, a nosso ver, interferiram no enquadramento do assassinato de Mayara como feminicídio. A dificuldade na aplicação da lei está no apego a padrões sociais e a determinados comportamentos que se ditam como legítimos para as mulheres. Se mulheres subvertem essa escala social, é como se merecessem ser punidas e perdessem o direito à defesa.

Além disso, as ocorrências de violência contra a mulher acabam sendo mais facilmente reconhecidas como crime quando ocorrem dentro de uma estrutura familiar, quando praticada pelos companheiros ou ex. É interessante, nesse contexto, acionar a denominação crimes de proximidade, conforme sugerem Martins e Carvalho (2016, p. 132), para não se limitar às noções de crimes passionais nem àquelas circunstâncias tradicionalmente consideradas, ampliando o espectro de crimes contra mulheres "tanto em suas dinâmicas de ocorrência, quanto no estabelecimento de critérios para sua apreensão estatística". Apesar da Lei do Feminicídio deixar explícita que a relação íntima não é pré-requisito para o enquadramento do crime, é sob esta perspectiva que as investigações policiais ocorrem.

No caso de Mayara, a relação não convencional entre ela e o assassino foi um fator que dificultou no reconhecimento de crime contra a mulher. A vítima não tinha um relacionamento formal com o assassino, não morava com ele, não tinha uma relação publicamente assumida, que resultasse, por exemplo, na existência de um histórico de violência, elementos que costumam caracterizar os casos de feminicídio.

A definição dada pelas Diretrizes para investigar, processar e julgar com perspectiva de gênero as mortes violentas de mulheres (ONU, 2016) não deixa dúvidas quanto ao caráter íntimo da relação entre Mayara e o assassino. $\mathrm{O}$ documento, que visa promover o aprimoramento da investigação policial, do processo judicial e julgamento desses crimes, coloca como feminicídio a morte de mulher cometida por pessoa com quem a vítima tenha tido vinculo íntimo, como marido, companheiro, amante. "Inclui-se a hipótese do amigo que assassina uma mulher - amiga ou conhecida - que se negou a ter uma relação 
íntima com ele, seja sentimental ou sexual" (PRADO; SANEMATSU, 2017, p. 21). Há ainda o feminicídio não íntimo, reconhecido como morte de mulher cometida por homem desconhecido, como "uma agressão sexual que culmina no assassinato de uma mulher por um estranho. Considera-se, também, o caso do vizinho que mata sua vizinha sem que existisse, entre ambos, algum tipo de relação ou vínculo" (Ibid., p. 21). Nesse sentido, a tipificação deve ser considerada em qualquer caso que envolva o assassinato de mulheres, sucedida, obviamente, por uma precisa investigação.

Para tipificar adequadamente o crime, é preciso compreender como as razões de gênero influenciaram ou não no desfecho fatal. A análise das circunstâncias, dos meios e modos empregados para a prática do crime, assim como as características do agressor e da vítima e o histórico de violência podem ajudar a revelar as razões de gênero por trás do assassinato de uma mulher. (Ibid., p. 53)

No assassinato violento de Mayara foi possível identificar razões de desigualdades de gênero como, por exemplo, a tentativa de limitação profissional e econômica, já que o autor roubou o carro e instrumentos de trabalho da vítima. Também é evidente o desprezo pela mulher e pelo feminino na forma como ocorreu o crime. As marteladas despendidas justamente na cabeça de Mayara são muito emblemáticas. É como se o autor tivesse a intenção de destruir o cérebro da vítima, portanto, a sua autonomia intelectual. Além disso, o corpo foi jogado em um matagal vestido apenas de calcinha e, posteriormente, incendiado, negando à vítima a preservação física - sua beleza por assim dizer -, mesmo depois de morta. Assassinatos com requintes de crueldade são característicos nos casos de feminicídio, bem como, o uso de instrumentos que causam dor e sofrimento à vítima.

A leitura dos elementos que fizemos aqui não foi isolada, mas amparada por uma série de manifestos e reivindicações de grupos feministas pela internet, que pressionou as investigações e, sobretudo, a mídia convencional. A abordagem midiática começou então a mudar com a vigilância das redes sociais digitais e a multiplicidade de vozes e interpretações que, atuando na contrainformação, fizeram os veículos de comunicação repensarem suas coberturas e propiciaram a abrangência nacional do caso.

\section{'Cadê meu celular? Eu vou ligar no 180'}

Acreditamos necessário aqui contextualizar brevemente a dinâmica do ciberjornalismo, uma vez que tratamos de cibermeios, e lembramos Castells (1999), que já previa 
a entrada da internet nas redações jornalísticas como um fator para aumentar a complexidade da atuação dos profissionais, que passaram a lidar com uma estrutura em rede, e a partir de fluxos comunicacionais de muitos para muitos. Isso resultou em novas formas de produção de informação, possibilidade de interação e mecanismos colaborativos.

Para Schwingel (2012), os fatores estruturantes do ciberjornalismo, como reconfiguração da mídia tradicional, mudança na dinâmica da rotina de produção, compartilhamento de conteúdos e a criação de novos modelos de negócio resultam em um fazer jornalístico empenhado em se adaptar às possibilidades e experiências proporcionadas pelo ciberespaço. Além da alteração na forma de produzir e consumir informações, também muda a participação da sociedade na construção e vigilância dos conteúdos midiáticos, que ficam cada vez mais intensas, especialmente, vemos aqui, no que se refere aos direitos humanos.

Padilha (2012) indica que nos ciberjornais existe um crescimento dos espaços e, assim, tudo parece ser noticiável. Tal característica faz com que as estratégias de agendamento mudem, alerta a autora (Ibid., p. 207). “O conteúdo noticioso publicado na internet tem dinâmica muito peculiar. Dinâmica que, historicamente, colocou em xeque alguns preceitos de publicação da notícia, como os relacionados à atualização, ao direcionamento da leitura, ao arquivamento e à pesquisa".

Para cidadãos e jornalistas, a avalanche de informações e o acesso a diversas formas de produzir e difundir notícias provocam diferentes impactos e a própria desconstrução da lógica da agenda-setting ${ }^{4}$. Sites de redes sociais digitais, ferramentas de participação, produção colaborativa de informações dão voz a diferentes grupos, que ganham protagonismo e indicam a constituição de diferentes fluxos de agendamento. A sociedade civil se mobiliza de modo a sensibilizar e atingir diretamente os meios de comunicação convencionais, a fim de fomentar a produção de notícias de interesse. Silva (2010 apud LAGO; BENETTI, 2010, p. 85) afirma que "pode-se, então, afirmar que o contra-agendamento de um tema pode ser parte de uma mobilização social; parte de um plano de enfrentamento de um problema, coorporativo ou coletivo".

4 Dentro dos estudos sobre os efeitos dos meios de comunicação na sociedade, Maxwell McCombs e Donald Shaw levantam a hipótese da Agenda-Setting, a partir de pesquisas realizadas com o objetivo de analisar a influência da mídia na decisão dos eleitores durante a campanha presidencial dos Estados Unidos, em 1968 (TRAQUINA, 2000). Com isso, dimensionou-se a capacidade do jornalismo exercer influência na opinião pública, ou seja, o que a mídia seleciona e divulga é o que faz parte das preocupações do conjunto do público. Mas outras variáveis devem ser consideradas, como o impacto da função do agendamento, que depende da necessidade de orientação do receptor. O fluxo de influência também não é unilateral; devemos considerar a capacidade da própria sociedade organizada ou não de agendar a mídia (contra-agendamento, conceito que nos interessa sobremaneira e tratamos no artigo) e dos próprios veículos se agendarem entre si (interagendamento). 
Observamos, empiricamente, que seguindo essa dinâmica, a cobertura sobre o caso Mayara Amaral nos ciberjornais escolhidos sofreu impactos, a partir de postagens em redes sociais digitais, e foi diretamente agendada pela mobilização nesse ambiente, em especial pela postagem de Pauliane Amaral, irmã da vítima, que contou com mais de 30 mil compartilhamentos. No post, ela questionou as versões oficiais, fez duras críticas à cobertura jornalística, utilizando, inclusive imagens e trechos publicados pela mídia local, e reivindicou o uso do termo feminicídio para um crime explicitamente motivado pelo ódio e relação de gênero. Foi nesse momento que os jornais locais deram início às discussões sobre feminicídio e tentaram questionar o enquadramento latrocínio. Em âmbito nacional, a postagem também foi determinante e conseguiu pautar veículos como $E l$ País e Folha de S.Paulo.

Identificamos aqui um contra-agendamento que acontece, justamente, pelo ciberespaço ser um ambiente dinâmico, de múltiplas vozes, que fomenta a participação do usuário na construção da informação.

No ciberespaço todos esses princípios são potencializados [...]. Diante disso, e da possibilidade que o cidadão comum, visto aqui como um público virtualmente em potencial, tem de emitir suas próprias percepções, questionando constantemente as regras e as verdades postas, os papéis historicamente atribuídos ao jornalismo também passam por rupturas. Funções como as de discussão de ideias contrárias, dar voz à opinião pública, ser os olhos e ouvidos dos cidadãos para discussão da cena política e agir como "cão de guarda" para perceber os abusos do poder são relativizadas, uma vez que dentro de novos espaços midiáticos de interação podem ser dividias com o público. Assim, o próprio jornalismo, através das empresas e profissionais que o representam, passa a ser vigiado, reacendendo uma antiga questão: qual o papel social do jornalismo? (SÉKULA, 2015, p. 192)

\section{'Vou entregar teu nome e explicar meu endereço'}

Considerando então as interpretações do enquadramento feminicídio e a capacidade da internet em alterar a lógica de construção das notícias (PADILHA, 2012), na sequência, apresentamos uma análise exploratória e descritiva de quatro textos veiculados por diferentes ciberjornais, nos atentando para o conteúdo em si e em como contribuiu (ou não) para o entendimento do caso e de suas correlações.

Campo Grande News, 26 de julho de 2017: "Mayara foi espancada até a morte em motel por dupla que queria roubar carro. Trio foi preso pelo crime na tarde desta quarta-feira (26); entre os envolvidos está um músico, que teria um relacionamento com a jovem". (RODRIGUES; BOGO, 2017) 
O Campo Grande News é o mais acessado ciberjornal ${ }^{5}$ da capital de Mato Grosso do Sul, publicou notícias desde a revelação do crime e das primeiras declarações da polícia, dia 25 de julho de 2017. A reportagem selecionada, do dia seguinte, traz elementos para além dos factuais, evidencia a repercussão dos fatos e pauta os pretensos esclarecimentos oficiais, portanto, mostrou-se pertinente para análise que visa o entendimento de uma cobertura jornalística em transformação.

De imediato, notamos que em momento algum foi citado o termo feminicídio ou problematizada essa tipificação. $\mathrm{O}$ título, inclusive, justifica o crime como sendo um roubo seguido de morte e não coloca em evidência a condição de mulher da vítima. $\mathrm{O}$ subtítulo reitera essa interpretação, informa sobre a prisão dos acusados ("envolvidos") e ressalta o relacionamento que um deles teria com a vítima. A justa proximidade da vítima com seu algoz já configuraria o feminicídio, mas, na interpretação do ciberjornal, acabou por funcionar como um elemento paliativo ou mesmo um risco assumido, já que logo no lead ( $1^{\circ}$ parágrafo), é informado que a emboscada foi feita depois que a jovem aceitou ir para um motel, informação repetida/reforçada no parágrafo seguinte (Ibid.).

Todo o texto, de conteúdo predominantemente noticioso, apesar de se tratar de um desdobramento, é pautado na versão oficial do delegado e nas alegações dos próprios "suspeitos" - ora envolvidos -, denominados assim, mesmo com a acusação direta das investigações policiais. Traz um relato dos acontecimentos e das versões dadas publicamente em coletivas e entrevistas. O discurso assumido busca certa neutralidade (ou mesmo imprecisão) ao não assumir os fatos e privilegiar os verbos no condicional, como nos exemplos "teriam mantido relações sexuais"; "teria sido espancada", "teria chegado a enterrar o corpo" (Ibid.).

Há um intertítulo que sugere a contextualização dos acontecimentos, com a retranca "O caso". O trecho explica o desaparecimento da mulher, "após brigar com o namorado", mas apresenta uma colagem de informações dadas anteriormente, apesar de constar no rodapé da página que a matéria, no momento da nossa análise, foi editada para incluir informações. Observamos uma negligência na edição jornalística, com dados defasados, declaração provisória da delegada, que atendeu a ocorrência (portanto, não estava mais no caso), sobre os pretensos sinais de pancadas na cabeça da vítima, sendo que a reportagem em si já abordava as conclusões policiais. Nesse sentido, vale a constatação da subutilização dos recursos da internet e das próprias possibilidades do ciberjornalismo em atualizar e retificar informações em tempo real. Na mesma retranca, há os dois parágrafos finais que se preocupam em explicar que o corpo carbonizado causou

5 Dados do site www.similarweb.com, tendo como referência o mês de julho de 2017, indicam média de dois milhões e trezentas mil visitas mensais. 
incêndio na vegetação e chamou atenção de fazendeiros que acionaram a polícia, mas não há uma linha contextualizando quem era a mulher assassinada de forma tão brutal.

O texto, escrito por duas jornalistas, coloca em xeque a atuação das profissionais, e o próprio compromisso social do jornalismo, já que não se atentaram às especificidades do caso e ou não tiveram o discernimento, alicerçado no conjunto das técnicas e da ética profissional, para reconhecerem um crime que ocorreu exclusivamente pela condição de mulher. Vale ressaltar que, posteriormente, no levante das redes sociais o ciberjornal pautou a questão do feminicídio e tentou discutir o caso sob nova ótica, mas não alterou as publicações anteriores.

Folha de S.Paulo, 29 de julho de 2017: "Assassinato de jovem professora a marteladas choca MS e 3 são presos” (FRIAS, 2017).

$\mathrm{Na}$ Folha de S.Paulo, a matéria aqui analisada também foi a única publicada sobre o caso, em 29 de julho. Ela começa descrevendo quem era Mayara, ressaltando, principalmente, o talento da musicista, sua juventude e o quanto era estimada pela família e amigos. A matéria, de gênero predominantemente informativo, construída por uma jornalista, usa em um primeiro momento declarações de fontes que confirmam esses aspectos, como ex-professor de música, prima e amiga. Constrói o ambiente para que o público leia e visualize o talento e juventude interrompidos com a morte, utilizando como apoio, inclusive, dois vídeos em que a musicista aparece tocando violão (Ibid.).

Embora feito superficialmente, percebemos que, dentre os conteúdos analisados, esse foi o único que se preocupou em apresentar a vítima, mostrando quem era Mayara e abrindo, assim, espaço para a humanização da mulher brutalmente assassinada, e tentando romper com o discurso adotado por outros ciberjornais até então, que, além de responsabilizar a vítima, centraram a atenção na descrição do crime em si.

No título podemos observar a atenção dada à grande repercussão do caso em Mato Grosso do Sul, fato que motivou o jornal de circulação nacional a cobrir o tema também. Nesse sentido, em uma segunda parte da narrativa, o ciberjornal aborda o caso a partir da comoção que o crime provocou. É apresentado o fato de a Polícia Civil ter indiciado os três "suspeitos" por latrocínio e ocultação de cadáver, ressaltando a indignação do texto postado no Facebook pela irmã de Mayara, que contesta essa tipificação. A partir daí, o jornal se dedica a descrever o crime, alternando parte do depoimento da irmã da musicista com as declarações dos envolvidos e da polícia. A matéria usa o termo feminicídio em dois momentos, uma vez quando explica a indignação e comoção das pessoas nas redes sociais, mas tentando abster-se, na pretensa neutralidade jornalística, sem problematizar o uso do termo, como notamos no trecho: "Mas a irmã da jovem, a jornalista Pauliane Amaral, 31, contesta alguns pontos da versão do único suspeito que confessou o crime, e 
acredita que ela tenha sido vítima de estupro e feminicídio" (Ibid.). Posteriormente, a tipificação é colocada para explicar as penas previstas tanto para latrocínio quanto para feminicídio, o que reforça a ideia de que o uso de latrocínio seria mais justo por prever uma pena maior, de 20 a 30 anos de reclusão, enquanto o feminicídio prevê de 12 a 30 anos.

A matéria privilegia a polêmica envolvendo postagens e mobilizações nas redes sociais. Embora tente usar fontes próximas de Mayara e dar visibilidade não só à versão dos acusados e notas oficiais da Polícia, não problematiza o feminicídio, tampouco ressalta o fato de ter sido um crime com um recorte explícito de relação de poder e gênero.

El País Brasil, 29 de julho de 2017: "Mayara Amaral, a violonista de Campo

Grande morta duas vezes. Crime reacende debate sobre a tipificação do feminicídio no país e as dificuldades de aplicá-lo" (MARTíN, 2017).

No El País Brasil, foi a única publicação feita sobre o caso, pelo menos quatro dias após o crime, escrita por uma jornalista, e se pauta, mais especificamente, na repercussão da postagem realizada pela irmã da vítima, para realizar uma crítica à cobertura midiática dada ao caso, e questionar a punição. Um texto híbrido, no que se refere aos gêneros jornalísticos, que indica atender a própria dinâmica coloquial e efusiva das redes sociais digitais, já que apresenta um vocabulário fortemente opinativo, além de elementos interpretativos. Todavia, não se configura como uma reportagem, considerando de imediato a profundidade, extensão e pluralidade de fontes e pesquisas, que são próprias do formato, mas estão ausentes no texto em questão.

Logo o título já revela uma forte crítica ao andamento do caso e de sua visibilidade: a morte que acontece de fato e a morte simbólica, provocada pelos veículos de comunicação, em especial os locais, que desprezaram a vítima e sua condição de mulher. O subtítulo cita diretamente o feminicídio e propõe um debate, que toma forma ao longo do texto, mas não é aprofundado, já que está pautado em fontes oficiais (o delegado e sua decisão) e na própria irmã da vítima, tomada pela comoção do acontecimento (Ibid.).

Sobre a cobertura midiática criticada, a jornalista não apresenta exemplos concretos, mas a sugestão para buscar no Google pelas abordagens equivocadas - mais um sintoma do determinismo da internet e de seus recursos nos textos jornalísticos. Outro ponto tangenciado no texto, a tipificação feminicídio propriamente, é relativizada pelo amplo espaço dado ao delegado e pela própria construção argumentativa, que abona o enquadramento do caso como latrocínio, no sentido em que aumenta a pena e acelera a decisão da justiça (Ibid.).

Apesar da necessidade de ampliação desse debate, inclusive com especialistas e se pautando em outros casos e na urgência de um agravamento da tipificação, reconhecemos uma interessante denúncia sobre uma cobertura que culpabiliza a vítima, busca 
justificativas para a barbárie e dá mais espaço para as versões dos acusados. Também há preocupação em colocar dados informativos que evidenciam a urgência do tema, como a morte de 13 mulheres por dia no Brasil, segundo o Mapa da Violência (WAISELFISZ, 2015). A opinião e pertinente condenação, de um jornalismo que toma partido e cumpre seu papel, são evidenciadas nos adjetivos e alusões como "brutal assassinato", "como de um animal", "duramente criticado". Ou na sentença: "O feminicídio é o nome para escancarar a violência que a mulher sofre todos os dias pelo simples fato de ser mulher, mas não só." E no questionamento: "Por que no Brasil é mais grave matar alguém para roubar um carro do que acabar selvagemente com a vida de uma mulher?" (MARTÍN, 2017).

Revista Veja, 15 de agosto de 2017: "A confissão do assassino de Mayara: 'Fui movido pelo ódio'. Em entrevista a VEJA, Luís Alberto Bastos Barbosa conta como matou, a golpes de martelo, a violonista e depois ateou fogo em seu corpo em um terreno baldio" (CAMPBELL, 2017).

A revista Veja optou por utilizar dois suportes para abordar o caso do assassinato da musicista Mayara Amaral. Na versão impressa, foi utilizado o gênero reportagem, enquanto a versão on-line trouxe, no dia 15 de agosto de 2017, uma entrevista no estilo pergunta-resposta, realizada por um jornalista, com conteúdo que configura um "furo" jornalístico (Ibid.). O termo é utilizado no meio para se referir a uma notícia dada em primeira mão, com exclusividade, nesse texto, em específico, está a confissão do assassino e sua total responsabilização pelo crime.

O material, na nossa interpretação, é dedicado a criar uma imagem vitimizada do autor do crime e reproduz problemas recorrentes na imprensa ao abordar casos de violência contra a mulher. As críticas podem ser feitas a partir do título: "Fui movido pelo ódio". Embora dê destaque ao caráter exclusivo do material, ao colocar a declaração do acusado, para apresentar o conteúdo ao público, é como se o jornalista trouxesse uma justificativa para o crime e tentasse, de certa forma, amenizar o ocorrido. “'Ataque de ciúmes', 'perdeu a cabeça', 'estava fora de si', 'ficou transtornado', 'teve um surto', 'ataque de loucura', estas são as principais alegações para 'justificar' um feminicídio e [...] são reproduzidas com grande destaque pela imprensa" (PRADO; SANEMATSU, 2017, p. 143).

Embora o uso do formato entrevista seja uma boa estratégia para tirar do jornalista a responsabilidade pelo apelo emocional do conteúdo, percebemos outros elementos que não estão necessariamente ligados à fala do entrevistado, mas que reforçam o caráter justificatório do conteúdo. A fotografia utilizada traz o autor do crime em primeiro plano. O ângulo permite identificar os olhos do autor fixados na câmera, que estão inchados e levam a supor choro e sofrimento, em uma tentativa de sensibilizar o leitor, 
reforçada pela legenda: "Encarcerado - O assassino de Mayara: 'À noite, eu grito por Deus"” (CAMPBELL, 2017).

Outro trecho da entrevista que demonstra uma tentativa de explicar o crime é quando o autor é questionado sobre suas motivações: "Fui movido pelo ódio porque tínhamos discutido e ela debochou da minha namorada. Chamei-a de vagabunda e ela me bateu. Tive um ataque de fúria, tinha bebido e cheirado. Depois que tudo aconteceu, chorei por mais de duas horas seguidas". Além de confessar que agiu agressivamente para reagir a um comportamento que não é socialmente esperado de uma mulher, ele cita o consumo de drogas para amenizar sua atitude.

$\mathrm{O}$ último questionamento feito pelo jornalista se refere ao arrependimento pelo crime: "Queria pedir desculpas à família da Mayara e à minha. Por mais que ninguém vá acreditar, eu gostava dela. Minha vida está destruída. Eu ia me casar, estava procurando casa, dei entrada para sacar o FGTS".

O predomínio da tentativa de justificar o crime e culpabilizar a vítima, poderia ser atenuado, por exemplo, ouvindo outras fontes ou com uma melhor contextualização do crime. Além do próprio assassino, a única fonte utilizada na introdução da entrevista é a delegada Gabriela Stainer, exclusivamente para endossar o furo jornalístico. O jornalista também não entra no mérito do crime ser enquadrado enquanto feminicídio ou latrocínio, deixando a entrevista ainda mais distante de contribuir para novas perspectivas sobre o caso. Um tipo de abordagem preocupante, uma vez que a mídia ainda exerce forte influência nas crenças, nos comportamentos sociais e no próprio processo penal. Martins e Carvalho notaram o mesmo procedimento em suas pesquisas realizadas em portais de noticias do Brasil e de Portugal no período de fevereiro a abril de 2015. A ausência de fontes especializadas na área jurídica, sociologia ou direitos humanos, por exemplo, para explicar marcos legais, conceituais e sociais do feminicídio, revelou uma tendência, mas uma certa ambiguidade na cobertura. "Os crimes não são negligenciados em suas ocorrências, mas são invisibilizados quanto às suas motivações". Com isso, eles concluem que a divulgação das tragédias é impulsionada "muito mais pela sensacionalização das notícias, com riscos de banalização dos crimes, do que pela proposição de debates em torno de estratégias políticas, socioculturais e comportamentais para o seu enfrentamento e desejável erradicação" (MARTINS; CARVALHO, 2016, p. 145).

\section{'Me deixem cantar até o fim'}

Constatamos pela avaliação exploratória das três notícias e da entrevista selecionadas que o tema feminicídio e todas as especificidades que envolvem esse crime ainda não foram 
incorporados pela imprensa, mesmo após dois anos de criação da lei que o tipifica. Na cobertura do caso Mayara Amaral, a versão de latrocínio dada pelos acusados e pela polícia foi amplamente repercutida pelos ciberjornais sul-mato-grossenses, deixando de lado, em um primeiro momento, qualquer relação com a violência de gênero, ainda que as matérias jornalísticas tenham relatado o fato de a vítima e o agressor manterem um relacionamento amoroso.

No ciberjonal local analisado, Campo Grande News, somente após a postagem da irmã da vítima que os termos feminicídio e estupro foram utilizados. Até então, como pudemos observar na matéria em xeque, se limitou a descrever o crime e reforçar a versão de roubo seguido de morte. Deixando de lado a possibilidade de, por estar no mesmo município em que aconteceu o crime, buscar novas fontes, contextualizar melhor o fato e questionar a versão das instituições oficiais. A cobertura mudou somente depois das publicações no Facebook, o que indica um forte agendamento das redes sociais no conteúdo jornalístico e reforça, cada vez mais, a participação e vigilância do público no trabalho midiático.

Esse agendamento foi percebido também nos jornais de circulação nacional $E l$ País e Folha de S.Paulo, que só publicaram notícias sobre o crime, quatro dias depois, levados pela ressonância da postagem da irmã da vítima. Nos dois veículos a abordagem se concentrou mais na descrição dos fatos e na declaração feita por Pauliane Amaral. O feminicídio aparece como algo reivindicado pela mobilização em rede, mas foi precariamente contextualizado e problematizado na construção das narrativas. Ou seja, a euforia e indignação das pessoas chamam a atenção dos jornais nacionais a ponto de cobrir um assassinado no interior do Brasil, mas o motivo dessa mobilização - que foi a reinvindicação como crime de feminicídio e denunciar a violência contra mulher -, pouco espaço teve.

Vale ressaltar que a única matéria que se dedicou a falar e descrever com mais detalhes quem era a Mayara Amaral foi a veiculada pela Folha de S.Paulo, mesmo assim, a maior parte da notícia foi construída com a descrição do crime e trechos de depoimento da internet.

Na Veja, o discurso de vitimização do agressor aliado às imagens, elemento trabalhado com mais intensidade por se tratar de uma revista, levam à interpretação de que a vítima foi responsável por sua morte. Percebemos na entrevista uma forte negligência aos fatos que caracterizam a violência de gênero, como o relacionamento amoroso que $o$ agressor mantinha com a vítima e a brutalidade com que Mayara foi assassinada. Ao dar voz para o acusado, que afirma ter agido por impulso e ódio momentâneo, causado pela própria vítima, a revista acaba banalizando o acontecimento e reforçando a ideia de que ele foi movido pela raiva e sob efeitos de drogas, deixando de lado qualquer possibilidade de ter sido uma tragédia causada pela condição de mulher. 
Observamos, em suma, que os conteúdos jornalísticos analisados ficaram centrados na descrição do crime e na versão oficial dada pela polícia, de roubo seguido de morte. Problematizando de forma incipiente a própria tipificação, as relações de gênero, e, acima de tudo, quem era a vítima desse crime brutal. Por isso, ainda que preliminarmente, concluímos que na cobertura midiática deste caso, a imprensa não colaborou no combate à violência contra a mulher e no entendimento do feminicídio. Deixando, assim, de pautar na sociedade a reflexão sobre uma temática urgente, ainda pouco compreendida e visibilizada.

Martins e Carvalho (Ibid., p. 127) avaliam que os crimes contra mulheres em relações de gêneros estão sujeitos aos regimes de visibilidade e invisibilidade, com isso, quando não despertam preocupação midiática "não raro dificultam ou mesmo impedem que as agressões físicas e ou simbólicas e as mortes delas decorrentes sejam compreendidas como feminicídios". Nesse sentido, urge a necessidade de ampliarmos nossas investigações em trabalhos futuros.

\section{Referências}

BRASIL. Lei n. 11.340, de 7 de agosto de 2006. Lei Maria da Penha. Diário Oficial da União, Brasília, DF, 8 ago. 2006. Seção 1, p. 1. Disponível em: <https://bit.ly/2IOp24n>. Acesso em: 25 maio 2018. Lei n. 13.104, de 9 de março de 2015. Altera o art. 121 do Decreto-Lei n. 2.848, de 7 de dezembro de 1940 - Código Penal, para prever o feminicídio como circunstância qualificadora do crime de homicídio. Diário Oficial da União, Brasília, DF, 10 mar. 2015. Seção 1, p. 1. Disponível em: $<$ https://bit.ly/2IOkaYZ>. Acesso em: 25 maio 2018.

CAMPBELL, U. A confissão do assassino de Mayara: "Fui movido pelo ódio". Veja, São Paulo, 15 ago. 2017. Disponível em: <https://abr.ai/2IRCznC>. Acesso em: 20 dez. 2017.

CASTELlS, M. A sociedade em rede. São Paulo: Paz e Terra, 1999.

FENAJ - FEDERAÇÃO NACIONAL DOS JORNALISTAS. Código de Ética dos jornalistas brasileiros. Brasília, DF: Fenaj, 2007.

FRIAS, S. Assassinato de jovem professora a marteladas choca MS e 3 são presos. Folha de S.Paulo, São Paulo, 29 jul. 2017. Disponível em: <https://bit.ly/2sdv2sn>. Acesso em: 20 dez. 2017.

GIL, Antonio Carlos. Como elaborar projetos de pesquisa. 5. ed. São Paulo: Atlas, 2010

MARTÍN, M. Mayara Amaral, a violonista de Campo Grande morta duas vezes. El País, São Paulo, 29 jul. 2017. Disponível em: <https://bit.ly/2IQDPrn>. Acesso em: 20 dez. 2017.

MARTINS, M. L.; CARVALHO, C. A. Crimes de proximidade contra mulheres em relações de gênero: dimensões políticas de um problema no Brasil e em Portugal a partir da cobertura jornalística. In: PRIOR, H.; GUAZINA, L.; ARAÚJO, B. (Orgs.). Diálogos lusófonos em comunicação e política. Covilhã: Universidade da Beira Interior, 2016. p. 125-148. 
ONU - ORGANIZAÇÃO DAS NAÇÕES UNIDAS. ONU Mulheres. Diretrizes Nacionais Feminicídio. Brasília, DF: Secretaria de Política para as Mulheres, 2016. Disponível em: <https://bit.ly/1Savq1w>. Acesso em: 30 set. 2017.

PADILHA, S. Os valores-notícia no webjornalismo. In: LONGHI, R.; D’ANDRÉIA, C. (Orgs.). Jornalismo convergente: reflexões, apropriações, experiências. Florianópolis: Insular, 2012. p. 199-217.

PRADO, D.; SANEMATSU, M. (Orgs.). Feminicídio: invisibilidade mata. São Paulo: Instituto Patrícia Galvão, 2017.

RECUERO, R. Redes sociais na internet. Porto Alegre: Sulina, 2010.

RODRIGUES, L.; BOGO, A. Mayara foi espancada até a morte em motel por dupla que queria roubar carro. Campo Grande News, Campo Grande, 26 jul. 2017. Disponível em: <https://bit.ly/2KVBWtQ>. Acesso em: 20 dez. 2017.

SAFFIOTI, H. I. B. Gênero, patriarcado e violência. São Paulo: Fundação Perseu Abramo, 2004.

SCHWINGEL, C. Ciberjornalismo. São Paulo: Paulinas, 2012.

SÉKULA, R. J. A paródia do jornalismo contribui para sua crise? In: Questões para um jornalismo em crise. CHRISTOFOLETTI, R. (Org.). Florianópolis: Insular, 2015.

SILVA, L. M. Sociedade, esfera pública e agendamento. In: Metodologia de pesquisa em jornalismo. BENETTI, M.; LAGO, C. (Orgs.). 3. ed. Petrópolis: Vozes, 2010.

TRAQUINA, N. O poder do jornalismo: análise e textos da teoria do agendamento. Coimbra: Minerva, 2000.

WAISELFISZ, J. J. Mapa da Violência 2015: homicídio de mulheres no Brasil. São Paulo: Instituto Sangari, 2015. Disponível em: <https://bit.ly/2LixlmB>. Acesso em: 30 set. 2017. 